\title{
Determinants of shoppers' checkout behaviour at supermarkets
}

Received (in revised form): 8th September, 2008

\section{Mario J. Miranda}

is the course coordinator in the retail management stream of the Business degree at Victoria University, Melbourne, Australia. His areas of research include studies on buying behaviour at the point of purchase. His interest in this area largely stems from his experience as a corporate executive and consultant with the retail industry. This paper formed part of his work towards a greater understanding of the mindset of distinct segments in a multicultural buying cohort when making purchasing decisions in the store.

\section{Keywords checkouts, aisles, supermarkets, shopping frequency, impulse buying}

\begin{abstract}
There is a general belief that products bought at store checkouts are selected on hasty inclinations. This study indicates that checkout purchases are commonly influenced by store-visit frequencies. Not all checkout purchases can casually be referred to as impulsive because what items shoppers select at checkouts indicate conscious concern with making efficient use of their shopping time.

Journal of Targeting, Measurement and Analysis for Marketing (2008) 16, 312-321. doi:10.1057/jt.2008.23; published online 3 November 2008
\end{abstract}

\section{INTRODUCTION}

The last decade had seen an explosion of new products and brands stocked in supermarkets. As a consequence, supermarket shoppers have increasingly got used to making selections from a plethora of product varieties and assortments displayed on store shelves. While the principal displays in store aisles provide consumers a wide choice from a vast array of products, it is intriguing that shoppers are prepared to restrict their options to a limited number of stock keeping units (SKUs) when they make their pick at checkouts.

There is no gainsaying that the checkouts are a valuable space area in the store because the customer is almost held captive in that spot. ${ }^{1}$ As a consequence, grocery retailers are being challenged to increase the number of assortments at checkouts and understandably, spend billions of dollars on advertising at the checkout. ${ }^{2}$ The

Correspondence: Mario J. Miranda, School of Applied Economics, Victoria University, Footscray Park Campus, PO Box 14428, Melbourne, Victoria 8001, Australia.

Tel: +6139919 5004;

Fax: +6139919 4888; significant number of purchases of around 2 per cent of total grocery sales ${ }^{3}$ vindicates the massive promotion of products at checkouts. Considering that the costing for this prime space in the store inevitably gets top billing in an era where increasing costs of retail space itself is putting retail margins under pressure, it is small wonder that retailers should care about the mix of merchandise that they display at checkout counters. Checkout counters command consumers' captive attention and checkout space should justifiably capture some of the highest return on investment of stock displayed in those areas. Various stock displayed at the checkouts have different purchase potential in that area. It is therefore a moot point whether grocery retailers' commitment of the most expensive area of the store, to certain products that do not offer acceptable retail margins or to nongrocery items that may require involved decision making, can be considered judicious.

It is generally suggested in the literature that significant number of purchases at checkouts is bought on impulse. ${ }^{4,5}$ It is, however, possible that merchandise displayed at checkouts provide the appropriate cues to 'remind' shoppers of items 
they intended to purchase before entering the store. According to the Cobb and Hoger, ${ }^{6}$ such purchases cannot be considered as impulse purchases because they are not bought on a whim with little preplanning. Nevertheless, purchases from checkouts would invariably be made from a limited selection and it is therefore reasonable to believe that consumers could rue not having picked the item from a more extensive availability on the principal displays in the store aisles. This study seeks to uncover the motivation for grocery shoppers' preparedness to compromise on the range of products available in the principal display when they make their choice from a limited selection at checkouts because they have forgotten to pick the item from the main aisles.

\section{BACKGROUND}

According to the Point-of-Purchase Advertising Institute $1995^{7}$ study, a significant number of product choices are made at the store checkouts even when over two-thirds of purchase decisions are made in the store itself. The Front-End Focus report, which analysed consumer shopping behaviour and attitudes, informs us that the top categories purchased at the checkouts include chewing gums, mints, other confectionery, magazines and soft drinks. The report states that in these product categories, checkout sales represent 46 per cent of supermarket sales. Hart and Davies ${ }^{8}$ suggest that magazines sold at checkouts generate double the sales per square metre compared to those in a main aisle display. Other common categories at supermarket checkouts include chocolates, snacks, batteries, films, lip care, books, phone/gift cards, audio/ videocassettes. These products are predominantly low-involvement products that spark an immediate need and desire for fulfilment.

In recent times, supermarkets have begun to expand the array of products that they stock beyond groceries and it is not surprising to find items like CDs/DVDs, batteries, memory cards and recipe books ordinarily sold in specialty stores, being merchandised on supermarket shelves and checkouts. Often, however, these items displayed in supermarkets lack the deep assortments and knowledgeable sales assistance that specialist stores provide.

Nonetheless, Hoffman ${ }^{9}$ argues that if shoppers are inclined to make selections at checkouts they will compromise on the range and buy from the limited display if the items are compatible with their lifestyles. For instance, Hoffman claims that in order to catch the attention of the health conscious customer, retailers may include a limited variety of health bars, dried fruit packets into the displays at the checkouts.

\section{LITERATURE REVIEW}

This research was motivated by an intrigue of shoppers being comfortable limiting their choice of purchase to the limited range of merchandise available at checkouts when they have forgotten to pick the item from the main display. Items displayed at checkouts are apparently strong enough cues to urge shoppers to recognise/ reconsider their needs and provoke compulsive buying. While the recognition may be a necessary condition, it may not be, however, a sufficient condition to make actual purchase. ${ }^{10}$ The comfort of selecting an item forgotten to be picked from the main displays would ostensibly be different for different products because product category differences are known to elicit different shopping orientations. ${ }^{11}$ Traditionally consumer products, based on buying behaviour, are classified as convenience goods, shopping goods and specialty items. ${ }^{12}$ Convenience items typically have a low unit price and not being greatly affected by fashions and fads are purchased with the least amount of concern of product performance. Shopping items are products that shoppers usually would consider purchasing as indiscrete unless they spend some time and effort in comparing quality, price and style of the items. On the other hand, specialty items are those products that consumers demonstrate willingness to process information regarding the items' claims of performance.

Most often, the items displayed at checkouts are of low unit values, whose performance the shopper is familiar with and the pathway to purchase the item is through, as Petty and Cacioppo. ${ }^{13}$ call in the 'Elaboration Likelihood 
model (ELM)', the peripheral route of decision making. In this decision-making protocol, shoppers take reliance only on the secondary aspects of the item, like visibility and accessibility, in a passive way where little cognition is applied. According to Hart and Davies, ${ }^{8}$ shoppers sometimes deliberately skip aisles to minimise shopping time and on these occasions they are likely to forget to pick items they had planned to buy. To shoppers in a hurry long waiting times at checkouts could be, according to Grambois, ${ }^{14}$ a cause for impatience, frustration and possible anger of shoppers caused by long waiting time. Grambois believes that the choice of merchandise at checkouts is to distract shoppers and not meant to provide the opportunity to contemplate comparatives among brands, prices and variants. Logically therefore, items that require greater 'elaboration' in the shopping protocol, wherein shoppers cognise with various alternatives at some length, do not lend themselves for purchase at checkout counters. These high involvement products are better off being displayed in regular aisles where the shoppers can, through the central route of decision making, ${ }^{13}$ make informed decisions.

One would expect that high-traffic areas like checkout counters would provide greater exposure, leading to an increased potential to drive in-store decisions. Mere exposure at the checkout, however, does not guarantee that consumers will be influenced in their purchase decision-making process. Inman and Winer ${ }^{2}$ argue that time pressure, age, gender and need recognition can all be considered to influence shoppers' decision making. They suggest, for instance, that the effort of thinking increases with an individual's age. Therefore, the older shoppers are likely to be less inclined to process 'rushed' information at checkouts. Correspondingly, younger shoppers are expected to make more spot decisions at the point of purchase than older shoppers and be the predominant buyers of merchandise at checkouts. Since the responsibility for grocery shopping often seems to fall upon the woman of the household, ${ }^{15}$ women are more likely than men to make in-store decisions. ${ }^{2}$ Moreover, according to Crosby, ${ }^{15}$ the likelihood of an unplanned purchase tends to be greater if others accompany shoppers. The presence of others will maximise the need recognition, since it accumulates the need recognition of all consumers in the group. Whether age, gender and shoppers' companions are mediating influences on consumers making good their selection of items from checkouts, which they have forgotten to pick from the principal displays is an arguable point.

\section{RESEARCH PROBLEM}

It is reasonable to believe that consumers would rue not having picked their intended purchases from the main display aisles. This study is based on the assumption that shoppers are prepared to make their choice from a limited selection at checkout displays because they have forgotten to pick the item from the main aisles.

This study seeks to uncover the motivation for grocery shoppers' preparedness to compromise on the range of products available in the principal display when they make their choice from a limited selection at checkouts because they have forgotten to pick the item from the main aisles. The question directed at shoppers was as follows: You bought these items from the checkout counter because you forgot to select them in the aisles: Yes/No.

\section{RESEARCH METHODOLOGY}

The research methodology included the personal administration of a structured questionnaire seeking the attitude and behaviour towards checkout purchases of eight items, among 626 randomly selected shoppers across Melbourne, exiting two of Australia's biggest supermarkets, namely, Safeway/Woolworths and Coles. Only those respondents who in the last six months had bought at least one of the items, picked from the store checkouts, were allowed to complete the survey. The items included in the survey were those that are conventionally displayed at supermarket checkouts, namely, magazines, recipe books, CDs/DVDs, batteries, memory cards, beverages and confectionery. Each of these eight items ostensibly has a different impulse or unplanned purchase potential based on buyer's perception of the risk of the item's purchase. 
Brands of beverages and confectionery are generally supported by relatively high advertising expenditures with the intention of creating consumer brand loyalty. Specific magazines, recipe books, CDs/DVDs are preferred by consumers depending on their lifestyles, and preferences for particular cuisines and genre of music/cinema, respectively. Most purchases of these items are made from specialist stores. Also, empirical evidence suggests that several grocery shoppers find it convenient to purchase conventional batteries and memory cards from supermarkets.

This investigation was conducted over a twoweek period in the third quarter of 2007. The respondents were asked to check the items that they purchased at the checkout counters, their level of satisfaction with the waiting time at the checkouts, what influenced their decision to pick the item(s) at the checkouts, whether they were satisfied with the range of items displayed at checkouts, the frequency with which they used the express line and whether they were buying the item(s) from the checkout on instruction. The questionnaire sought information about variables on shopper behaviour, such as the customers' frequency of shopping, proneness to price specials, inclination to switch to alternate brands, the size of the bill, and selected demographics like gender, occupation and age. These variables (with the exception of shopping time, gender and age) are not specifically referred to in extant studies on checkouts. These variables are, however, included in the research investigation as they are considered to have a mediating influence on shoppers' response to the mix of items included at checkouts.

By combining three defining dimensions of shopper's behaviour - their purchase orientations, the contextual situations of their purchases and shoppers' demographics, we estimated the motivations of shoppers to select items from supermarket checkouts that they might have disregarded or forgotten at the aisles.

This research seeks to examine the relative consumer cognition and affectation that different products chosen from the checkout attract. The focus is on the following binary variable:
FORGAIS: You bought these items from the checkout counter because you forgo to select them in the aisles: (Yes/No) or $(1 / 0)$.

We have modelled this dichotomous dependent variable (FORGAIS) with a Binary Logit regression model (see eg Hair et al., Chapter 5). ${ }^{16}$ Thus, the coefficients would reflect the impact of the independent variables on the likelihood of the shopper buying specific items from the checkout counter because they forgot them in the aisles. The theoretical model is presented as follows.

\section{Model}

The probability of observing a value of the dependent variable was modelled as

$$
y_{i}^{*}=\beta_{0}+\beta_{1} x_{1, i}+\beta_{2} x_{2, i}+\cdots+\beta_{K} x_{K, i}+\varepsilon_{i}=\mathbf{X}_{i} \boldsymbol{\beta}+\varepsilon_{i}
$$

The dependent variable, $y^{\star}$, is assumed to be linearly related to a set of explanatory variables, $x_{1}, x_{2}, \ldots, x_{K}$, where $\mathbf{X}_{i}$ is an $n \times K$ matrix of $n$ observations on the $K$ explanatory variables, $\boldsymbol{\beta}$ is a $(K+1) \times 1$ vector of the coefficients and $\varepsilon_{i}$ is a stochastic error term.

The binary model is often presented as a latent variables specification. The latent variable can be some unobserved measure ascribed by the respondent. Then, the observed dependent variable, $y$, is determined by the following rule:

$$
y_{i}= \begin{cases}1 & \text { if } y_{i}^{*}>0 \\ 0 & \text { if } y_{i}^{*} \leq 0\end{cases}
$$

The combination of expressions (1) and (2) yields the following binary regression model:

$$
\begin{aligned}
P\left(y_{i}=1 \mid \mathbf{X}_{i}\right) & =P\left(y_{i}^{*}>0 \mid \mathbf{X}_{i}\right) \\
& =P\left(\mathbf{X}_{i} \boldsymbol{\beta}+\varepsilon_{i}>0 \mid \mathbf{X}_{i}\right)=F\left(\mathbf{X}_{i} \boldsymbol{\beta}\right) \\
P\left(y_{i}=0 \mid \mathbf{X}_{i}\right) & =P\left(y_{i}^{*} \leq 0 \mid \mathbf{X}_{i}\right)=1-F\left(\mathbf{X}_{i} \boldsymbol{\beta}\right)
\end{aligned}
$$

where $F$ is the cumulative probability distribution function of $\varepsilon_{i}$. With regard to this error term, there are many possible choices, but the two most popular options are the standard normal and logistic random variables. In the latter case, $F$ is 
the cumulative standard logistic distribution function:

$$
F\left(\mathbf{X}_{i} \boldsymbol{\beta}\right)=\frac{\mathrm{e}^{\mathbf{X}_{i} \boldsymbol{\beta}}}{1+\mathrm{e}^{\mathbf{X}_{i} \boldsymbol{\beta}}}
$$

Owing to the cumulative distribution function, the effects of the explanatory variables on the dependent variable are nonlinear. For that reason, the unknown parameters of this model are estimated by the maximum likelihood procedure that maximises the likelihood that an event (FORGAIS) will occur. Thus, the estimated coefficients cannot be interpreted as the marginal effect of the explanatory variables on the dependent variable. The signs of the regression coefficients, however, determine the directions of these effects. Positive values of the coefficients imply that the probability of FORGAIS $=1$ is an increasing function of the corresponding explanatory variables, while a negative parameter estimate implies the opposite.

\section{DATA ANALYSIS}

It was intended initially to relate the dependent variable, FOR GAIS, to the following dummy and ranked explanatory variables:

GENDERM: Respondent's gender (0: male);

GENDERF: Respondent's gender (1: female);

GRSTOREY: Do you buy most of your groceries from this store? (1: yes);

GRSTOREN: Do you buy most of your groceries from this store? (0: no);

STLOYAL1-STLOYAL3: How long have you been shopping at this store? (1: less than 6 months, 2: 6-12 months, 3: more than 1 year);

SHMONTH: How often do you shop at this store? (1: monthly);

SHFORTN: How often do you shop at this store? (2: fortnightly);

SHWEEK: How often do you shop at this store? (3: weekly);

SHMOREONCE: How often do you shop at this store? (4: more than once a week);

BROMERCH1: Do you browse merchandise displayed at checkouts? (1: at every visit);

BROMERCH2: Do you browse merchandise displayed at checkouts? (2: sometimes);
BROMERCH3: Do you browse merchandise displayed at checkouts? (3: never);

BROREASON: You browse merchandise at a checkout it is because (1: nice way to keep occupied, 2: forgotten to buy from aisle, 3: both (1) and (2));

BUYCHECKOUT1: Do you buy merchandise displayed at a checkout? (1: at every visit);

BUYCHECKOUT2: Do you buy merchandise displayed at a checkout? (2: sometimes);

BUYCHECKOUT3: Do you buy merchandise displayed at a checkout? (3: never);

READING: Do you buy the following merchandise displayed at checkouts? (1: magazines/recipe books);

CONFBEV: Do you buy the following merchandise displayed at checkouts? (2: confectionery/ beverages);

MEMBAT: Do you buy the following merchandise displayed at checkouts? (3: memory cards/batteries);

DVDCD: Do you buy the following merchandise displayed at checkouts? (4: CDs/DVDs);

EXPOFTEN: How often do you use 'express line' checkout? (1: often);

EXPSOMET: How often do you use 'express line' checkout? (2: sometimes);

EXPNEVER: How often do you use 'express line' checkout? (3: never);

NICE: When you browse merchandise at a checkout it is because (1: nice way to keep occupied);

NOTFORGOT: When you browse merchandise at a checkout it is because (2: deliberately ignored item in the aisle);

DECMAKER: If you buy merchandise at a checkout, it is because (1: you are the decision maker);

COMPINFLUEN: If you buy merchandise at a checkout, it is because (2: you are influenced by your companion);

LESSTHAN50: Size of your weekly grocery bill (1: less than $\$ 50)$;

51-100: Size of your weekly grocery bill (2: between $\$ 51$ and 100);

101-150: Size of your weekly grocery bill (3: between $\$ 101$ and 151);

YESSPECIAL: Do you generally buy items that are on 'special'? (1: yes);

NOSPECIAL: Do you generally buy items that are on 'special'? (2: no); 
RANGEYES: Were you satisfied with the range of products offered at the checkout? (1: yes);

RANGENO: Were you satisfied with the range of products offered at the checkout? (2: no);

WAITVERSATIS: How satisfied are you with the waiting time at the checkout? (1: very satisfied);

WAITSOMESATIS: How satisfied are you with the waiting time at the checkout? (2: somewhat satisfied);

WAITNOTSATIS: How satisfied are you with the waiting time at the checkout? (3; not satisfied);

STUDENT: Your occupation (1: student);

HOMEDUTY:Your occupation (2: home duties);

WHCOLLAR:Your occupation (3: white collar);

BLCOLLAR:Your occupation (4: blue collar)

LOOK4WK: Your occupation (5: looking for work);

RETIRED: Your occupation (6: retired);

AGE1-AGE5:Your age group (1: less than or equal to $20,2: 21-35,3: 36-50 ; 4: 51-65 ; 5$ : more than 65);

HSEHLD1-HSEHLD5: Your household size (1: 1-3, 2: 4-5, 3: more than 5).

Almost 36 per cent of respondents, that is, 224 shoppers claimed to buy at the checkout more than one item category at a time. In order to accommodate (within a relatively small sample size) a large number of degrees of freedom, we considered it prudent to restrict our analysis to those respondents who only bought only one item category, that is, 400 respondents. Of these respondents, 324 (81 per cent) respondents claimed to have purchased the item from the checkout because they had forgotten to pick it from the main aisle. Each shopper is exemplified by the item category that they have purchased at the checkout. Given below are the groupings of product categories that supposedly satisfy the generic need of the items:

1. Magazines/cookbooks

2. Confectionery/beverages

3. Batteries/memory cards

4. CDs/DVDs

\section{ESTIMATION RESULTS}

A Binary Logit model was estimated for the dichotomous dependent variable, FOR GAIS. Only responses from shoppers who considered the supermarkets from which they exited as their principal stores were considered in the prepared data set. The first step included the estimation of the regression model without restricting the specifications in the prepared data set. Using a stepwise regression, the independent variables that appeared to be less important and proved insignificant both individually and jointly, were subsequently dropped from the model. The maximum likelihood parameter estimates of the final, 'restricted' specification are reported in Table 1.

The variables that emerged as significant at 1,5 and 10 per cent level in influencing the likelihood of buying specific items from the checkout counter because the shopper forgot to select them in the aisles (FORGAIS) were from the following group of variables (see Table 1 for the specific significant variables):

- Frequency of shopping (monthly, SHMONTH; fortnightly, SHFORTN; weekly, SHWEEK; more than once a week, SHMOREONE).

- Frequency of using 'express line' checkout (often, EXPOFTEN; sometimes, EXPSOMET; never, EXPSONEV).

- Reason for browsing merchandise at checkouts (it is nice way to keep occupied while waiting in the queue, NICE; may have disregarded item from the aisle, NOTFORGOT).

- The average size of the weekly grocery bill (less than $\$ 50$, between $\$ 51$ and $100,51-100$; between $\$ 101$ and 150,101-150; more than $\$ 150)$.

The goodness-of-fit for the model is indicated by the $\log$ likelihood value and Cox\&Snell $R^{2}$ provided in a standard SPSS output. As it is evident from Table 1, the quality of models for individual categories of products is not very high, but is considered acceptable for field data.

The findings in Table 1 with respect to the signs of the coefficients, imply that the estimated probability of buying magazines/cookbooks (READING) from the checkout counter because 
Table 1: Estimation results for Logit model

\begin{tabular}{|c|c|c|c|c|c|c|c|c|}
\hline & \multicolumn{2}{|l|}{ READINGS } & \multicolumn{2}{|l|}{ CONFBEV } & \multicolumn{2}{|l|}{ MEMBAT } & \multicolumn{2}{|l|}{ DVDCD } \\
\hline & Coefficient & Significant & Coefficient & Significant & Coefficient & Significant & Coefficient & Significant \\
\hline \multicolumn{9}{|c|}{ Dependent variable: FORGAIS } \\
\hline SHMONTH & 0.959 & $0.045^{\star \star}$ & & & & & & \\
\hline SHFORTN & 1.040 & $0.005^{\star}$ & 1.201 & 0.000 & -1.043 & 0.068 & & \\
\hline SHWEEK & & & & & -1.721 & $0.008^{\star}$ & -1.515 & $0.020^{* *}$ \\
\hline SHMOREONE & & & & & -2.334 & $0.002^{*}$ & -1.771 & $0.038^{\star \star}$ \\
\hline EXPOFTEN & & & -0.870 & $0.077^{\star \star \star}$ & -1.270 & $0.059^{\star \star *}$ & & \\
\hline EXPSOMET & 2.497 & $0.000^{*}$ & 2.042 & $0.000^{\star}$ & 2.761 & $0.000^{\star}$ & 2.981 & $0.000^{*}$ \\
\hline NICE & -1.487 & $0.000^{*}$ & & & & & & \\
\hline NOTFORGOT & & & 1.432 & $0.000^{*}$ & & & & \\
\hline $51-100$ & & & & & -1.064 & $0.026^{\star \star}$ & -2.308 & $0.000^{*}$ \\
\hline $101-150$ & 1.141 & $0.009^{\star}$ & & & & & & \\
\hline Log likelihood & -252.411 & & -228.735 & & -148.669 & & -92.662 & \\
\hline Cox\&Snell $R^{2}$ & 0.206 & & 0.231 & & 0.289 & & 0.351 & \\
\hline
\end{tabular}

*Significant at the 1 per cent level; ${ }^{* *}$ significant at the 5 per cent level; ${ }^{* *}$ significant at the 10 per cent level

In the category of DVDs and CDs (DVDCD), it also appears that an increase in the likelihood of selecting DVDs and CDs from checkouts because these items were forgotten to be picked from the aisles, increases as shoppers take greater advantage of the express line (EXPSOMET). In contrast, the likelihood of selecting DVDs and CDs from checkouts because these items were forgotten to be picked from the aisles increases as the frequency of shopping (SHWEEK, SHMOREONE) reduces. On the other hand, the likelihood of selecting DVDs and CDs from checkouts because these items were forgotten to be picked from the aisles is reduced with a low value of the weekly grocery bill (51-100).

the shopper forgot to pick them from the aisles increases if shoppers feel that browsing through magazines/cookbooks from the checkout is NOT a nice way to keep occupied while waiting in the queue (NICE, negative coefficient). The likelihood of buying magazines/cookbooks from the checkout counter because these items were forgotten in the aisles increases with less frequent store visits (SHMONTH, SHFORTN), more use of express lines (EXPSOMET), and increasing value of the weekly grocery bills (101-150).

The estimated probability of buying confectionery and beverages (CONFBEV) from checkouts because the shopper forgot to pick them from the aisles increases when shoppers browse checkouts because they have deliberately ignored these in the aisles (NOTFORGOT). The likelihood of consumers buying confectionery and beverages from the checkout counter because they forgot to select these items in the aisles also tends to increase when shoppers visit the stores less often (just once in a fortnight, SHFORTN). There is also evidence that the inclination of shoppers to select confectionery and beverages from the checkout counter because they forgot to select these items in the aisles is high when shoppers make greater use of express lines (EXPSOMET).
The frequency of shopping (SHFORTN, SHWEEK, SHMOREONE) has a negative effect on the probability buying of buying memory cards and batteries (MEMBAT) from checkouts because the shopper forgot to pick them from the aisles. In other words, the likelihood of selecting memory cards/batteries from checkouts because these items were forgotten to be picked from the aisles increases with the reduced number of store visits. Similarly, a low value of the shopper's weekly grocery bill $(51-100)$ tends to reduce the likelihood buying memory cards and batteries from the checkout counter because they were forgotten in the aisles. The likelihood of selecting memory cards/batteries from checkouts because these items were not picked from the aisles, however, increases as shoppers take more advantage of the express line (EXPSOMET).

The estimation results are presented in Table 1.

\section{DISCUSSIONS AND IMPLICATIONS}

This study is predicated on the assumption that shoppers are prepared to make their choice from a limited selection at supermarket checkout displays because they had forgotten to pick the item from the main aisles. An overwhelmingly large number of grocery shoppers (81 per cent) confirmed that having purchased the item from the checkout 
because they had forgotten to pick it from the main aisle. Notably, there was no evidence of shoppers feeling restrained to select their purchases from the checkouts because they felt the limited availability of merchandise (RANGEYES/RANGENO) on offer at the payment counters. What shoppers purchased at checkouts appears to be commonly influenced by consumers' store-visit frequencies. The emphasis on the frequency of shoppers' supermarket trips as an important driver of whether they select and what they choose, at the checkouts, is an indication of the importance that shoppers ascribe to the shopping time that they spend at the stores. It appears from this study that once shoppers have moved away from the principal aisles where particular items are stocked, and front up to pay at the checkout counters, they no longer feel involved with the risk/benefit of a particular purchase, especially as shoppers do not appear to consider promotions and price specials as significant influence on their decisions to select particular items at the checkouts. The availability of time to make their next shopping visit to the principal aisle seems to dominate their cognition when making choices at the checkouts. Shoppers who are inclined to buy magazines and cookbooks at the checkouts, appear resentful of the notion that browsing through magazines/ cookbooks is a nice way of keeping occupied while waiting in the checkout queue, illustrating again that time is significant element that motivates their shopping experience at the checkouts. These shoppers presumably would prefer to be served quicker rather than have the latitude to browse through magazines/cookbooks while waiting to be served. Further vindication of shoppers' concern with shopping time was the demonstrated inclination of all shoppers to use the express counters.

These findings suggest that shoppers' purchases at grocery checkouts may not be spontaneous and unreflective as alluded by Rook and Fisher ${ }^{4}$, but demonstrative of conscious concern with making efficient use of their shopping time. Not all purchases at checkouts can therefore be casually referred to as impulse purchase.
While this study had no intention of examining the frequency of purchase of specific items from checkouts, it did emerge that more frequent supermarket shoppers are inclined to purchasing nongrocery items like batteries, memory cards and CDs/DVDs from checkout counters, in spite of their limited range. On the other hand, this study indicates shoppers who buy confectionery and beverages at checkouts are those who have deliberately ignored (NOTFORGOT) these items at the principal stocking points. Purchases of confectionery and beverages at checkouts can therefore be considered to be less contemplated and more impulsive, because buyers in case of these purchases appear comfortable with their hasty decisions at the front-end point of sale.

\section{LIMITATIONS OF STUDY AND FUTURE RESEARCH}

This research was based on an exploratory survey with a limited sample size. In order to accommodate the large number of degrees of freedom, multiple products that meet similar generic needs were combined to form a product category. The data analysis was compromised to the extent that only the combined categories were analysed instead of testing each item. Because of our lack of confidence of being able to recruit a larger number of respondents in a restricted period of time, the questionnaire was structured in such a manner that each respondent was required to have made a planned purchase of just one of eight items from the checkout. Consequently, because of the limited number of purchasers of each item, the study was compelled to consider only a limited sample (400 respondents) to compare the checkout experiences of each product category among the different respondents. With a larger sample size, a greater range of products that are conventionally stocked at the checkouts could also be tested. This research could be extended to studying the typologies of products at the checkouts of other store formats.

\section{CONCLUSION}

Checkout counters within a supermarket are known to represent significant sales and profit 
opportunities by driving incremental purchases. If an appropriate mix of items is not displayed at checkouts, retailers should be well aware that they might be exposing themselves to at least two risks, namely, compromise on the opportunity to earn better returns on items that benefit from a push at the point of sale and potential shopper dissonances from the hurried purchase of items that require deliberate decision making.

This study was predicated by the assumption that shoppers will generally buy from the checkouts if they have forgotten to make a selection from the regular aisles where the item is displayed. This assumption was driven by the logic that the alternative of picking the item from the checkout from a limited variety is considered a poor option and one that may cause shoppers to regret their forgetfulness. For many shoppers wheeling their trolley back into the aisle may not be a consideration, lest they lose their spot in the queue. In this shopping trip, purchase from the checkout might appear as an easy option, but which the shopper may ideally want to avoid through better organisation of their shopping list. In this mode of picking their purchase, it is quite conceivable that shoppers will buy only the bare necessity. This study, however, demonstrates that shoppers do not feel restrained by the limited range of merchandise at checkouts if they have forgotten to make their selection from the principal aisles.

Checkout counters do not generally offer the space to accommodate a large selection of items. It is not uncommon for retailers therefore to display at the checkouts only a selection of reading and entertainment items that dominate the current popularity poll. There is no gainsaying that these reading items require a fair amount of consumer cognition. Because the store checkouts are hamstrung for space, the merchandising effect of only a limited range and variety of magazines and recipe books at these points are often not compatible with the shopper's desired buying protocol of these items. It is therefore no surprise that shoppers prefer to browse these items at the regular aisles and spend time in contemplating their choices. In contradiction to popular belief, shoppers do not consider browsing/flipping through magazines at checkouts a good practice. Retailers, who encourage their patrons to go through magazines at the checkouts, may perversely be trying to distract shoppers' attentions from the travails of waiting in the queues to be served. Huddleston et al. ${ }^{5}$ believe that keeping shoppers longer at the checkouts is not going to encourage them buying any more at the checkouts but only makes them reconsider shopping at the store again. And if what shoppers buy at checkouts is influenced by the achievement of efficiency in shopping times, as identified in this study, delaying them at checkouts could be the very antithesis of maximising the return of investment of stock displayed at checkouts.

Considering that significant purchases of confectionery and beverages at checkouts may be bought on impulse, it is reasonable to assume that often these items could be considered mainly for their generic value. The high proportion of sale of confectionery items and beverages, from checkouts, unless they are of the dominant brands, suggest that consumers who patronise confectionery and beverages at checkouts are prepared to commodify this product category. As a consequence, lesser-known brands of confectionery and beverages can be considered for sale at checkouts, especially if these brands offer generous retail margins for the retailer's push effort. Future research could examine whether the generic value of store brands of confectionery and beverages would be good potential for retailers to merchandise at their checkouts. Against the background of the findings of this study that frequent shoppers are likely to buy nongrocery items like batteries and memory cards displayed at the checkout counters, it might be useful for future research to examine whether retailers could effectively use their checkout counters to merchandise store brands of nongrocery items, especially as supermarkets continue to expand their range of products outside groceries and food items.

Grocery shoppers, as we have seen in this study, are inclined to make their selections from checkouts as a rear guard action for their 
forgetfulness, and consequently seek the expediencies of shopping time-management rather than indulge in unreflective purchase when such needs are recognised in making buying decisions at checkouts. Supermarkets can get an insight into the shopping frequencies of patrons by tracking their purchases through their credit cards and store loyalty cards and accordingly configure the checkout merchandise mix that allow shoppers a chance to justifiably retrieve what they need without any pangs of regret. CamWeb reports that an overwhelming number of supermarket customers are using credit cards to pay for grocery purchases. This report also attests that a large number of retailers either participate in a loyalty programme or issue their own reward cards. Retailers can therefore measure the success of their merchandising strategy at checkouts by placing specially marked SKUs, which can be captured from purchases made by credit cards and store loyalty cards.

\section{References and Notes}

1 Levy, M. and Weitz, B. A. (2004) 'Retailing Management', McGraw-Hill, New York.

2 Inman, J. J. and Winer, R. S. (1998) "Where the rubber meets the road: A model of in-store consumer decision-making', Working Paper, Marketing Science Institute, California Marketing, pp. 98-122.

3 Front-End Focus (2006) 'Optimizing front-end merchandising', www.gmabrands.com/news/docs/NewsRelease.cfm?DocID=165, viewed on 8th April, 2008.

4 Rook, D. W. and Fisher, R. (1995) 'Normative influences on impulsive buying behaviour', Journal of Consumer Research, Vol. 22 (December), pp. 305-313.
5 Huddleston, P., Whipple, J. and VanAuken, A. (2004) 'Food store loyalty: Application of consumer loyalty framework', Journal of Targeting, Measurement and Analysis for Marketing, Vol. 12, No. 3, pp. 213-230.

6 Cobb, C. J. and Hoger, W. D. (1986) 'Planned versus impulse purchase behaviour', Journal of Retailing, Vol. 62 (winter), pp. 384-409.

7 The 1995 Point-of-Purchase Advertising Institute (POPAI), 'Consumer Buying Habits Explored in Recently Released Summary and Analysis of 1995 POPAI Study' in http:// www.422business.com/html2/articles/199603/marchcon.htm, viewed on 8th April, 2008.

8 Hart, C. and Davies, M. (1996) 'The location and merchandising of nonfood in supermarkets', International Journal of Retail and Distribution Management, Vol. 24, No. 3, pp. 17-25.

9 Hoffman, L. (2006) 'Australians battle world bulge', The Australian, 7th February, http://www.parentjury.org.au/tpj_news. asp?ContainerID=1802, viewed on 29th March, 2007.

10 O'Dougherty, M., Story, M. and Stang, J. (2006) 'Observations of parent-child co-shoppers in supermarkets: Children's involvement in food selections, parental yielding, and refusal strategies', Journal of Nutrition Education and Behaviour, Vol. 38, No. 3, pp. 183-188.

11 Vijayasarathy, L. R. and Jones, J. M. (2000) 'Intentions to shop using Internet catalogues: Exploring the effects of product types, shopping orientations, and attitudes towards computers', Electronic Markets, Vol. 10 (January), pp. 29-38.

12 Murphy, P. E. and Enis, B. M. (1986) 'Classifying products strategically', Journal of Marketing, Vol. 50 (July), pp. 24-42.

13 Petty, R. E. and Cacioppo, J. T. (1983) 'Issue involvement can increase or decrease persuasion by enhancing message-relevant cognitive responses', Journal of Personality and Social Psychology, Vol. 37, pp. 1915-1926.

14 Granbois, D. H. (1968) 'Improving the study of consumer in-store behaviour', Journal of Marketing, Vol. 32, pp. 28-33.

15 Crosby, F. J. (1991) 'Juggling: The Unexpected Advantages of Balancing Career and Home for Women and Their Families', The Free Press, New York.

16 Hair Jr., J. F., Black, W. C., Babin, B. J., Anderson, R. E. and Tatham, R. L. (2006) 'Multivariate Data Analysis', 6th edn, Chapter 5, Pearson Education, Inc., Upper Saddle River, NJ.

17 CamWeb (2006) 'Reward cards', http://www.cardweb.com/cf/, viewed on 13th March, 2007. 